\title{
Das cavernas às prateleiras: sobre pigmentos, maquiagens e filtros ${ }^{1}$
}

\author{
Gabriela Reinaldo' \\ https://orcid.org/0000-0003-3663-0314 \\ I - Universidade Federal do Ceará. \\ Fortaleza (CE). Brasil.
}

Resumo: Assim como o reconhecimento facial é uma capacidade ancestral do intelecto humano que garante nosso pertencimento a um determinado grupo e, portanto, a nossa própria sobrevivência (SACKS 1997, 2010; LEONE, 2016; 2018), além da nossa vinculação emocional (CYRULNIK, 1995) também há evidências de que os primeiros hominídeos modificavam voluntariamente suas aparências, disfarçando, camuflando ou criando outras versões de si mesmos capazes de se endereçar aos deuses, aos seus contemporâneos e à natureza. A manipulação do rosto, embora se trate de uma prática arquetípica, diz respeito às mudanças nas mídias historicamente constituídas (BELTING, 2015). Midiaticamente, não apenas o rosto é a imagem mais reproduzida e consumida na atualidade - ou seja, o rosto está, de modo ubíquo, na mass media -, mas o próprio rosto é uma mídia (BELTING, 2007). Este artigo se dedica a discutir as alterações faciais temporárias - como maquiagens e filtros de aplicativos. Além disso, abordaremos de que maneira, mesmo quando se trata de uma atividade desencantada, ainda se verificam traços de um passado místico, mágico e ritualístico na maquiagem e no ato de se maquiar - vestígios que aparecem, por exemplo, no discurso da publicidade de cosméticos.

Palavras-chaves: maquiagem; filtros; reconhecimento facial; rosto; mídias; publicidade de cosméticos.

Abstract: From caves to shelves: on pigments, makeup and filters - In the same way that facial recognition is an ancestral capacity of the human intellect that guarantees our belonging to a certain group and, therefore, our own 
survival (SACKS 1997, 2010; LEONE, 2016; 2018), in addition to our emotional bond (CYRULNIK, 1995) there is also evidence that the early hominids voluntarily modified their appearances, disguising, camouflaging or creating other versions of themselves capable of addressing the gods, their contemporaries and nature. The manipulation of the face, despite being an archetypal practice, concerns changes in the historically constituted media (BELTING, 2015). Regarding media, not only is the face (is) the most reproduced and consumed image nowadays - the face is ubiquitously in the mass media - , but it is itself a media (BELTING, 2007). This paper discusses the temporary facial changes - such as makeup and application filters. In addition, we will approach how even dealing with a disenchanted activity, there are still traces of a mystical, magical and ritualistic past in makeup and in the act of putting makeup on - traces that appear, for example, in the discourse of cosmetics advertising.

Keywords: make-up; filters; facial recognition; face; media; cosmetics advertising.

Quando pintamos, descolorimos ou modificamos a estrutura ou o desenho dos pelos do rosto e dos cabelos, quando usamos máscaras ou outros adereços sobre a face, quando maceramos, moemos ou raspamos raízes, folhas, cascas, vísceras ou minérios a fim de obtermos um pigmento para colorir nossa pele, tensionamos o par natureza e cultura. Mais do que simplesmente refazer o que estava previamente estabelecido pelo código genético, responsável pelos traços fenotípicos, modificamos a parte mais significativa da nossa aparência no que diz respeito ao reconhecimento pelos nossos pares: o rosto. O reconhecimento facial é uma faculdade cerebral responsável, entre outras funções, pelo pertencimento a uma determinada tribo, povo ou nação que assegura a sobrevivência do indivíduo em meio às adversidades do ambiente (SACKS 2010; CYRULNIK, 1995) e os vínculos afetivos (CYRULNIK, 1995).

Desse modo, evolutivamente, os indivíduos que reconheciam rostos se sobressaíam em relação àqueles cujas capacidades cognitivas não os habilitavam ao reconhecimento facial dos seus pares (LEONE, 2016; 2018). Hoje sabemos que a prosopagnosia (prosopon - rosto, agnosia incapacidade de identificar ou reconhecer) atinge, em maior ou menor grau, 2\% da população mundial (SACKS, 2010) e que, no cérebro humano, há zonas específicas dedicadas ao reconhecimento da face (SACKS 1997, 2010). Ainda assim, atentamos contra o que nos assegura conforto e pertencimento e modificamos nossas faces. Essas mudanças intencionais são uma demonstração de que, para além da sobrevivência física, nossas ações são orientadas para um outro tipo de sobrevivência, a sobrevivência simbólica - sustento que é promovido por elementos afetivos, psíquicos, emocionais, ideológicos, políticos, históricos e culturais. 
A manipulação proposital da aparência tem suas origens no alvorecer da humanidade e reprograma, permanentemente, a esfera ou o universo dos signos, o que Lotman (1990) denominou semiosfera. Ao produzirmos signos, não apenas representamos o que seria "o real", mas o recriamos - e assim nos inserimos como coautores da instável (porque permanentemente barganhável) programação do par natureza x cultura. Quando nos disfarçamos, negociamos e trapaceamos e, ao mesmo tempo, também nos revelamos. Inserimos na semiosfera informações que entrarão na disputa entre o que merece ser reconhecido, decodificado e inserido no patrimônio da memória e o que cairá no limbo do esquecimento, do não semiotizável, do amorfo.

A manipulação das faces - quer a manipulação permanente, com escarificações, tatuagens ou procedimentos bucomaxilofaciais cirúrgicos, ou mesmo a temporária com o uso de adereços, maquiagens e pinturas sobre a pele - concorre com o próprio tempo pelo controle das alterações da aparência. Na maioria dos animais, a modificação da aparência se dá pelas mudanças de fases, observadas desde o nascimento, passando pelo período reprodutivo, envelhecimento e morte. Há ainda animais cujas mudanças de pelagens, cascas, asas ou escamas obedecem ao calendário das estações, e há os que mudam de aparência em função das condições climáticas de uma determinada paisagem geográfica ou - como é o caso dos aquáticos - em função de elementos como o $\mathrm{pH}$ do meio, a pressão atmosférica ou a incidência de luminosidade. No ser humano, a modificação volitiva da aparência, de modo a impedir, dificultar ou retardar o reconhecimento pelos seus pares ou a ressignificar sua própria existência ou status dentro de uma determinada comunidade, se dá, principalmente, pela manipulação do próprio rosto.

Atualmente, é praticamente impossível falar de manipulações das faces sem se levarem em consideração as mídias historicamente constituídas. Midiaticamente, não apenas o rosto é a imagem mais reproduzida e consumida na atualidade - ou seja, o rosto está, de modo ubíquo, na mass media -, mas o próprio rosto é uma mídia². Mídia aqui entendida conforme

2 Na classificação de Harry Pross (1990), que divide as mídias em primárias, secundárias e terciárias em função dos suportes ou aparatos a partir do próprio corpo do sujeito (um corpo medial), o rosto se constitui como uma mídia primária. Mídias primárias são as que dispensam suportes, apêndices, e que cumprem sua função no tempo presente da performance comunicativa. Também Hans Belting (2007), ao defender uma iconologia que leva em conta a tríade corpo, mídia e imagem, discute o rosto e o corpo como uma forma de mídia. Sobre o tema, publiquei "As faces de Hans Belting", no livro Imagem e exercício da liberdade: cinema, fotografia e artes, em 2020, e "Rosto na mídia e rosto como mídia: as contribuições de Hans Belting para o estudo do rosto", publicado na Revista Famecos, em 2019 - referências completas ao final deste artigo. 
a etimologia do termo - do latim, media, plural de medium, meio ou veículo. Este artigo se dedica a investigar as modificações faciais temporárias, especialmente no que dizem respeito ao uso de maquiagens, cosméticos e aos filtros de aplicativos de celular, e como essa produção de rostos conflui para a estigmatização dos indivíduos e para a replicação de faces em série.

\section{Das cavernas às prateleiras: os químicos e a relação telúrica e mágica}

No prestigiado periódico Current Anthropology, Lawrence Barham, professor do Centro de Pesquisa Evolucionária Humana do Departamento de Arqueologia da Universidade de Bristol, publica, em 2002, os resultados de uma das mais revolucionárias descobertas arqueológicas sobre o uso de minérios na Idade da Pedra Média. Essas descobertas, mais do que contribuírem para o estudo das idades geológicas do solo, impactaram os debates sobre a evolução da cultura simbólica humana.

Em 1996, três peças de óxido de ferro e uma de hidróxido de ferro (hematita e limonita ou limonite) foram encontradas no sítio arqueológico de Twin Rivers, na Zambia Central - material que motivou expedições que tiveram início em 1999. Nessas escavações, ocorridas de julho a agosto, bolsões de sedimentos revelaram uma grande amostra de minerais que fornecem evidências ligadas não à fabricação de objetos de caça ou a outra atividade de caráter prático, mas ao uso simbólico e ritualístico voltado para a criação e manutenção das identidades de grupo. Segundo os achados, que continham pigmentos e objetos de moagem, a principal função da coleta e processamento de minerais seria a extração de pigmentos. Os hominídeos dedicavam-se a arrancar a cor da terra e transferi-la para seus corpos.

Em Twin Rivers, o material data, geologicamente, de níveis do solo que correspondem a 300.000 anos atrás. Ou seja, muito antes da ascensão e dispersão do Homo sapiens pelo planeta. De acordo com Barham, o uso de pigmentos também abrange o período transicional do Homo sapiens arcaico (como o Homo heidelbergensis, H. rhodesiensis ou H. helmei) para o Homo sapiens sapiens. Além disso, as manchas em ferramentas de pedra encontradas no local indicam que os primeiros hominídeos estavam moendo pigmentos ocres muito antes de serem usados em pinturas rupestres ${ }^{3}$. Dentre os objetos encontrados pela

3 A S. Connor (2009), dr. Barham explica: "Until now, the only unambiguous use of color in symbolic art is found in our own species in the form of rock art, beads and pigments - such as the famous cave paintings of Lascaux in France. In Europe the earliest cave art appears no earlier than 40,000 years ago, long after Homo sapiens originated in east Africa about 200,000 years ago". 
expedição de Barham, peças demonstravam desgastes como se tivessem sido esfregadas para produzir um pó - indício de um uso intencional e sistemático da coleta e do processamento de pigmentos por um longo período de tempo pelos hominídeos no Pleistoceno médio.

Além dessas descobertas na África Central, chamam atenção os achados ao sul do continente africano no ano de 2000. Os pigmentos de terra encontrados em escavações nas Cavernas do Pinnacle Point, um pequeno promontório na costa da África do Sul, revelam a presença de humanos na Idade da Pedra Média entre 170.000 e 40.000 anos atrás. Estes humanos, assim como os de Twin Rivers, faziam uso de minérios a fim de obterem pigmentos para pinturas corporais com finalidades ritualísticas. Em The pigments from Pinnacle Point Cave 13B, Western Cape, South Africa, artigo publicado na Journal of Human Evolution, e na Encyclopedia of Geoarchaeology (capítulo 'Pigments), lan Watts (2010; 2015) diz que o uso mais comum dos pigmentos, do ponto de vista etnográfico, está ligado às pinturas corporais e cosméticos. Outros usos seriam o decorativo, além de ter sido encontrada uma ampla gama de artefatos de uso ritualístico, como roupas, ferramentas e pinturas nas paredes de cavernas. Watts afirma ainda que há robustas provas de que a moagem preferencial era de materiais avermelhados, mais saturados e escuros, sendo o ocre o material mais ubíquo na Idade da Pedra Média.

A questão era se o ocre teria sido usado para a pintura, como um agente de escurecimento da pele ou se teria um uso prático (como se fosse uma cola ou cimento de sustentação para a fabricação de objetos). Em outras palavras: se seu uso predominante se daria por causa da cor ou se o material teria sido valorizado graças às suas características funcionais, uma vez que os tons de ocre derivam do óxido de ferro - pigmentos avermelhados e amarelados geralmente referidos como ocre retiram sua cor da hematita (óxido de ferro que produz tons avermelhados) e da goethita (o óxido de ferro responsável pelos tons acastanhados, alaranjados e amarelados).

Para Elizabeth J. Himelfarb (2000), o professor Barham contou que nos locais onde foram realizadas essas escavações, havia à disposição outros materiais mais macios e de fácil extração para as funções práticas:

a variedade de cores usadas em Twin Rivers e suas diferentes fontes e necessidade de processamento me levam a crer que uma explicação puramente funcional para sua presença simplesmente não é suficiente. Por que se preocupar em coletar e moer um tipo particularmente duro 
de óxido de ferro quando um material mais macio que está por perto funcionaria tão bem como um preservativo de couro ou remédio? Era a cor que se procurava, não o teor do ferro em si (tradução nossa)

Watts $(2010,2015)$ afirma que a recorrência dos avermelhados de tonalidade sanguínea para a humanidade em seu estágio pré-histórico - e as descobertas na Pinnacle Point Cave demonstravam que esses povos faziam esforços consideráveis para conseguir esse tom - é uma evidência significativa do comportamento simbólico ligado à indústria de cosméticos pré-histórica ${ }^{4}$. Segundo o autor, no Pleistoceno Médio há a mudança do uso irregular do pigmento vermelho-sangue para um uso mais sistemático e onipresente - período que coincide com o amadurecimento e sofisticação do cérebro humano (circa 200.000). Os dados dessa pesquisa também corroboram a tese de Durkheim, diz Watts, que, em As formas elementares da vida religiosa, afirma a centralidade do uso de pigmentos avermelhados na cultura em função dos rituais.

O que nos dizem essas descobertas a respeito dos processos comunicativos e simbólicos? Sendo consenso entre cientistas acerca da nossa origem africana, esses achados lançam luzes sobre a importância dos cosméticos para as atividades simbólicas e ritualísticas humanas primevas. Esses pigmentos, inicialmente, não se destinavam prioritariamente à superfície das pedras ou dos utensílios, como se pensava, mas à pele humana. Os primeiros hominídeos coletavam e manipulavam cores para enfeitarem seus próprios corpos, para se camuflarem, para emularem, para criarem personagens, para se conectarem com deuses e deusas ou ancestrais e para - encobrindo - desvelarem outros eus que só se revelariam no disfarce ou na atuação ritualística.

O que essas descobertas confirmam é que a cultura simbólica está intimamente ligada à modificação das aparências. Confirmam também que a tecnologia de coleta e manipulação de elementos do meio ambiente - como minérios, mas também moluscos, cascas, frutos secos, vísceras, esterco de animais ou folhas de henna - atende a propósitos semióticos, que dizem respeito à mediação, à negociação sígnica, à substituição e criação de artifícios comunicativos.

\footnotetext{
4 Importante dizer que Ian Watts é, juntamente com os antropólogos evolucionistas Chris Knight e Camilla Power, defensor de uma teoria chamada Female cosmetic coalitions, a FCC. Ainda em fase de comprovação, a FCC se dedica a explicar a emergência da arte, dos rituais e da cultura simbólica na pré-história e trabalha com a hipótese de que as artes visuais mais ancestrais não estavam em superfícies - como as paredes das cavernas -, mas no próprio corpo humano.
} 
E, neste ponto, é preciso compreender comunicação como um processo cosmogônico, um processo de criação ou instituição de um cosmos que delimita, que cria fronteiras, no intuito de se separar do caos. Uma comunicação que, ao mesmo tempo, se endereça aos pares, aos que pertencem à mesma tribo, nação ou comunidade e se volta para a natureza e para as divindades. E nesse processo comunicativo, que é um processo de domesticação da realidade e criação de linguagens como mecanismos de estabelecimento de separação entre ordem e desarmonia, de distinção diante do amorfo ou indiferenciado, de sacralização do espaço e das atividades humanas significativas, estavam os cosméticos ou, pelo menos, os seus ancestrais.

Criada no século XVII, a própria palavra cosmético alude ao embelezamento mas também ao cosmos. Do francês, cosmétique é uma forma latinizada do grego kosmētikos; sendo kosmein arranjar ou adornar e kosmos um termo que se refere à ordem ou harmonia, kosmetike seria a arte (tekhnē) ou habilidade de vestir, adornar ou enfeitar. O ocre, o carbono negro (carvão) ou o lápis-lázuli, nesta perspectiva, não eram elementos aleatoriamente escolhidos apenas em função de suas propriedades químicas ou físicas, mas eram selecionados de acordo com necessidades semióticas, estéticas e ritualísticas.

Se as pinturas corporais têm suas origens ligadas ao conhecimento telúrico e religioso - como se sabe, a extração e uso de pigmentos estão ligados não apenas às cores e texturas obtidas, mas ao próprio elemento na natureza - , sangue, sementes, raízes, frutos e flores secos, vísceras, cascas de árvores e minérios exerciam poder sobre a pintura realizada. Para além do conhecimento empírico, a obtenção de uma determinada pasta, cera, resina ou pó estava ligada a uma profunda intimidade com a matéria, assim como seus modos de elaboração e usos. Pintar a própria pele para mimetizar um felino, um pássaro, uma deidade ou um ancestral mítico fazia parte de um conjunto de normas muito específicas de determinado grupo social que precisavam ser observadas para que o ritual acontecesse.

Atualmente, embora ainda conviva com as pinturas ritualísticas, a maquiagem no seu uso cotidiano, mundano e desencantado, não pressupõe a atuação num ritual sagrado. Além disso, o rosto maquiado não se destina apenas à acuidade do olho humano. Lentes e aparatos técnicos medeiam a percepção da face. Com as câmeras de fotografar e filmar, a maquiagem precisou se adequar às questões técnicas dos recursos disponíveis. Sequências mais longas e mais próximas do rosto de atores e atrizes no início do cinema 
nos Estados Unidos, por exemplo, só foram possíveis graças às invenções de Max Factor, que criou substâncias capazes de não craquelar e não provocar intoxicação quando aplicadas sobre a pele. O rosto humano, para parecer saudável e "natural" no telejornal ou numa live no Instagram, precisa estar coberto por algumas camadas de pó, cremes e ceras. Além dos filtros materiais, das camadas que recobrem a pele humana, há os filtros físicos (especialmente ligados aos tipos de lentes) e os digitais. Contudo, mesmo se tratando de uma atividade desencantada, ainda há traços desse passado místico, mágico e ritualístico na maquiagem e no ato de se maquiar. Esses vestígios aparecem, especialmente, na publicidade de cosméticos, como discutiremos neste artigo.

\section{A feérica aventura de Max Factor: do make up à make-up e ao make-believe}

Numa noite do gelado mês de fevereiro do ano de 1904, acossados pelo vento, pela neve e pelas vozes dos homens do czar que os caçavam, um boticário judeu de 27 anos de idade fugia com sua esposa e seus três filhos pequenos pela assustadora floresta russa. Poucos dias antes, o mesmo homem era o favorito da família real, estimado e disputado por toda a corte. Anos depois, seria não apenas o fundador de uma indústria milionária, mas também o revolucionário de técnicas que favoreceriam e modificariam radicalmente as artes da indústria cultural — especialmente do cinema — numa escala impensada até o momento. Nascido em Lodz, na Polônia, a história de Max Factor, de batismo Maksymilian Faktorowicz, um peruqueiro, farmacêutico, perfumista, bioquímico, negociante e cosmetologista de pouco mais de um metro e meio de altura, é contada por Fred E. Baster, na biografia intitulada Max Factor: The Man Who Changed the Faces of the World (Max Factor: o homem que mudou as faces do mundo), publicada pela editora americana Arcade, em 2008, com todas as nuanças de um conto de fadas.

Com a mesma entonação feérica, o escritor John Updike (2008) intitula sua resenha sobre o livro de Baster na revista The New Yorker: "Makeup And Make-Believe: Max Factor's life of beautification". Updike faz um trocadilho com a expressão "make up", que, com Max Factor, vira um substantivo. Ao batizar o "make-up", acrescentando um hífen, o mago das aparências incentiva as pessoas a desafiarem padrões de comportamento de uma época e reinventarem suas próprias faces. Untadas, empoadas e azeitadas, estreava 
o ritual do make-believe, agora permitido às pessoas comuns. O teatro já não seria mais o último refúgio da maquiagem (fora do palco, o gesto de pintar as próprias faces era compreendido, para a Europa e América branca, como uma momice caricatural, primitiva ou tribal). Com Max Factor, as mulheres americanas dos primeiros anos do século XX, superando os escrúpulos impostos por seus maridos, pais, empregadores - e até mesmo pela lei! ${ }^{5}$ -, começam a se pintar.

O maquiador polonês não apenas viveu aventuras que o aproximam dos heróis do cinema (de festejado pela elite russa a caçado e fugitivo e novamente incensado na América, de viúvo pobre com três filhos a magnata e inventor de um novo tipo de comércio), mas sua vida se confunde com o amadurecimento das técnicas da sétima arte. A entrada de M. Factor no "make-believe" aconteceu aos sete anos de idade, quando vendia doces no lobby do Lodz's Czarina Theatre e se encantava com artistas e passantes. Aos oito, vira assistente de farmacêutico; aos nove, aprendiz de peruqueiro e, aos treze, já atuava como profissional em cabelos. Esse currículo o leva, aos quatorze de idade, para Moscou, onde trabalha diretamente com o cosmeticista da Grande Ópera Imperial Russa. Com vinte e dois anos, Max Factor abre seu próprio negócio, num subúrbio de R'azan, quando uma trupe de teatro o descobre. Em poucas semanas, ele se torna um disputado conseIheiro e cosmeticista da aristocracia russa.

Ao mesmo tempo em que sua fama começa a se espalhar, o Czar Nicolau II ordena o cerco aos judeus. Temendo a perseguição, Max Factor consegue alcançar o vapor Molka III, que estava de partida para a América. Os elementos de sua fuga (que contaram com um composto espalhado na pele que enganou seus próprios médicos) fazem jus aos melhores thrillers cinematográficos - indústria que desconhecia até então, mas que viria a revolucionar no Novo Mundo. Já na América, novamente trabalhando nas artes e técnicas dos cosméticos, é atraído por artistas que atuavam num set de filmagens instalado nas proximidades do seu comércio. Naquele tempo, a caracterização dos atores era feita com compostos preparados com base em vaselina, farinha, banha, amido de milho e até mesmo em tijolo moído. Essas máscaras funcionavam bem para o olho distante do espectador de teatro, mas o close das câmeras mostrava os efeitos das expressões faciais esfarelando a cobertura. 


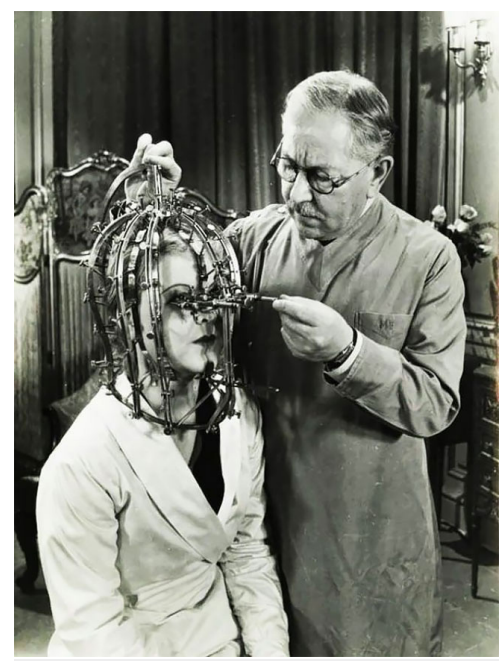

Figura 1. Max Factor beauty-calibrator ou calibrator machine ou ainda make-up aplicator. Fonte da imagem: https://designyoutrust.com/2018/11/ max-factors-beauty-calibrator-a-beautymeasuring-mask-analyzes-facial-flaws-formakeup-from-the-1930s/

Em 1914, Max Factor inventa um creme ultrafino em consistência e ao mesmo tempo espesso o suficiente para cobrir a epiderme. Além de funcional, Max Factor consegue produzir uma paleta com 12 gradações de cores. Esse experimento, que tornou o tecnicolor mais agradável, foi o catalizador do icônico pan-cake da Max Factor. Portátil, o creme das estrelas vinha numa embalagem charmosa e prometia uma aplicação descomplicada, o que fez desse item o maior sucesso comercial da Max Factor. Chaplin, Keaton e outras estrelas do dito cinema mudo são usuários dos seus compostos. Para Phyllis Haver, inventa os cílios postiços; com Douglas Fairbanks, se dá a primeira prova da resistência dos corantes à transpiração corporal; o efeito "blur" ou "smear" que imortalizou Joan Crawford também é legado de sua maestria alquímica e o galã Rodolfo Valentino recebe cobertura amarelada para simular uma pele mais bronzeada e saudável.

Quando, no final dos anos 1920, chega o som ao cinema, os microfones começam a captar o ruído barulhento das luzes. As novas lâmpadas, agora de tungstênio, eram mais silenciosas, mas também mais quentes. Os filmes ortocromáticos (sensíveis a todas as cores, com exceção do vermelho) não captavam apropriadamente a iluminação mais suave das lâmpadas de 
tungstênio. Na substituição pela película pancromática, as faces se tornavam mais escuras. Novos tons precisavam ser criados para dar conta da nova variedade de cores. O que funcionava bem no cinema em preto e branco ou com a película ortocromática, como os batons marrons, tornava-se artificial na vida real.

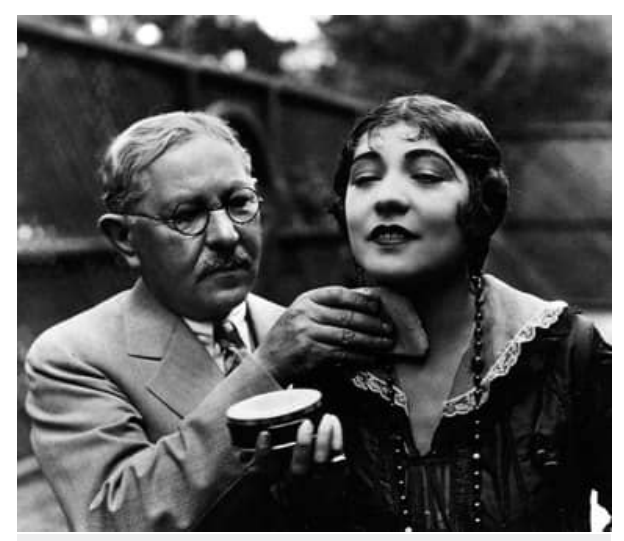

Figura 2. Max Factor testando uma maquiagem em Renée Adorée (Jeanne de la Fontein), em 1925. Fonte da imagem: http://www.cosmeticsandskin.com/

companies/max-factor.php

Pelo menos três elementos dessa trama são centrais para a história do rosto. O primeiro é: a história do rosto, é a história do conflito entre a "verdadeira face" e suas máscaras, uma vez que, como afirma o historiador da arte e estudioso da imagem Hans Belting (2015), o impulso à camuflagem e à modificação do rosto é tão antigo quanto a sociedade humana. O segundo, mais ligado à relação entre rosto e mídia, é: a história das mídias audiovisuais que se confunde com a história das técnicas de filmar e fotografar, mas também com a história dos cosméticos, com a química — ou com sua "ancestral" de reputação duvidosa dentre os ditos homens de ciência, a alquimia. Já o terceiro elemento diz respeito ao segredo - palavra recorrente nos anúncios publicitários de cosméticos, como abordaremos.

\section{Alquimia, astrologia, medicina, jurisprudência e mântica: a interpretação como forma de dominação e preconceito}

A Fisiognomonia (do grego physis, natureza, e gnomon, que quer dizer julgamento conhecimento ou interpretação), começa de modo mais sistemático, 
no Ocidente, no século XVII, embora uma literatura medieval propriamente dita date do XII. No início do Renascimento, as obras de Fisiognomonia estavam ligadas à alquimia, à astrologia (era costume identificar traços da personalidade comparando rostos com desenhos da constelação astral), à mântica e à medicina - esta, especialmente atada à teoria dos Quatro Humores (COURTINE; HAROCHE, 2007). Para o médico e humanista Giovanni Michele Savonarola, mesmo os cabelos diziam da disposição do espírito: abundantes para os de temperamento quente, ralos aos de temperamento mais frio, enquanto que a umidade excessiva do cérebro se traduziria em grandes e grossos narizes de pessoas de pouco asseio. G. M. Savonarola que viria a ser avô do dominicano Hieronymous (ou Girolamo) Savonarola, que ficou conhecido pela queima de objetos de arte em sua fogueira das vaidades -ajuntou à teoria Humoral a leitura das aparências com as bases astrológicas divinatórias: os órgãos humanos, os humores e o temperamento se correspondiam com o zodíaco. (COURTINE; HAROCHE, 2007).

Em The Speculum phisionomie by Michele Savonarola, Gabriella Zuccolin (2007) aponta cinco principais contribuições do autor para a Fisiognomonia renascentista: a sistematização desse saber no campo da medicina; sua utilidade para os governantes, que podiam escolher melhor seus ministros, servos e esposas; o desenvolvimento da noção matemática de proporção. Apoiado na descrição fictícia da aparência de Cristo da carta de Publius Lentulus, pretenso antecessor de Pôncio Pilatos, governador da Judeia, o Speculum de Savonarola, publicado em 1442, é o primeiro documento a descrever a fisionomia de Cristo e concebê-lo como espelho (speculum) do ser humano perfeito. As características clássicas do protótipo ideal são cristianizadas e oferecidas ao mundo ocidental como modelo a ser seguido.

Pouco mais de cem anos depois, em 1586, o alquimista e filósofo Giovanni Battista (ou Giambattista) Della Porta (1586), nascido em Nápoles no tempo da revolução científica e da Reforma Protestante, escreve seu De Humana Physiognomonia, um trabalho exaustivo, longo e sistemático que influenciaria toda a produção do século XVI e da primeira metade do século XVIII (COURTINE; HAROCHE, 2007). Homem da Renascença, Della Porta abraça, além das tradições árabes e latinas, os saberes populares e se vincula à doutrina hermética da assinatura das coisas - presente no medievo tardio que dizia "assim como é em cima, é embaixo" (sicut in caelo, et in terra), assegurando a existência de relações entre o macro e o microcosmo e à magia simpática, que age por correspondência e/ou similitude. Della 
Porta faz comparações zoomorfas, organiza e promove o diálogo, que já existia desde Aristóteles, entre a face humana e a face animal. No século XVII, Richard Saunders (1653) ecoa e amplia essas questões em sua obra Physiognomie, and Chiromancie, Metoposcopie.

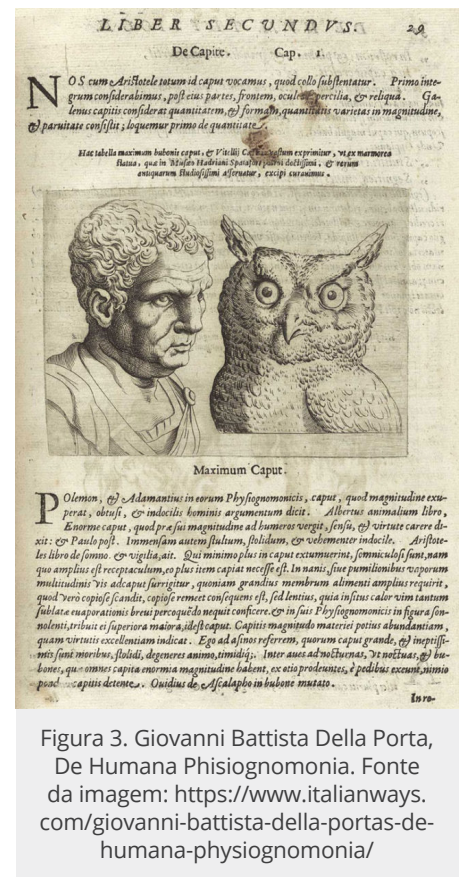

Na história brasileira, é preciso lembrar que a criação dos manicômios judiciários está ligada ao legado do italiano Cesare Lombroso (1835-1909). Fundador da ciência criminalista positivista, nascida do entusiasmo pelas ideias de seleção natural de Darwin (e distorcendo seu legado), Lombroso legitimava o discurso eugênico. Com bases imperialistas, neocoloniais e eurocêntricas, Lombroso propagava a "teoria do criminoso nato", que identificava nos traços faciais (especialmente de mestiços) a propensão à criminalidade ou à demência.

\section{I put a spell on you: o nome e a poção mágica}

Reafirmando a tendência em colocar público e celebridade mais próximos - o que se traduz em filtros, ceras e pigmentos "imperceptíveis", a chamada 
naked skin ${ }^{6}$ - abundam, no mercado, promessas de venda de uma pele saudável. Não é suficiente cobrir a pele de químicos, depois de desfolhá-la com outros químicos e procedimentos estéticos. É preciso garantir ao espectador-consumidor que ela está nua, limpa, pura, "levantada" e "clareada". Revitalift (algo que sugere revitalização mais levantamento - lembrando que lift em inglês, além de alçar/elevar/levantar, pode ser também alegrar, tornar mais interessante ou agradável) é o "rejuvenescedor facial" da marca L'Oreal. Nos rótulos, mesmo de produtos comercializados no Brasil, além de "fit" (ajustar) ou "lift" são comuns outros termos importados, como para dizer do clareamento (clarify) ou improve (melhorar, aperfeiçoar) - produto da brasileira Dermage.

Uma das maiores empresas cosméticas do mundo, a Avon, originalmente americana, fundada em 1886, mas assim batizada em 1939, tem uma linha de cosméticos que vai de cremes faciais, passando pelo batom e base, até cremes para pés e mãos chamada Renew (renovar, reavivar, rejuvenescer). Nesta, chamam atenção nomes como "Sérum reparador maximizador de Juventude", da linha Renew Smart (adjetivo que pode fazer supor uma certa hierarquia na qualidade dos produtos); Infinity Lift (cuja promessa de eternidade compete com nada mais nada menos do que a própria lei da gravidade) e Renew ultimate. Ultimate diz do que é elementar, fundamental, mas também alude a uma solução conclusiva, extrema, categórica, definitiva, inapelável. Mais do que isso, só o milagroso ou divino. E, sim, não faltam miracles - em inglês, mas também em bom francês - nos títulos dos cosméticos.

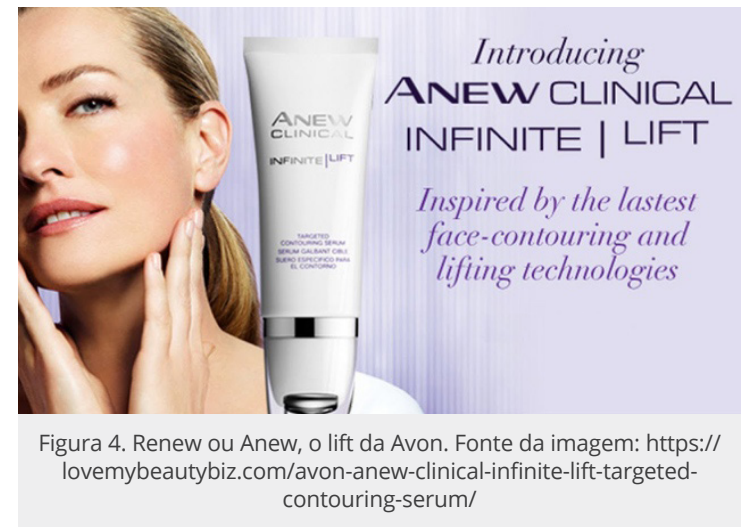

6 Sobre a pele nua (embora maquiada) e as estratégias discursivas que a associam ao ideal de pureza, escrevi "O rosto nu: a respeito do disfarce da maquiagem", publicado na revista Designis, em setembro de 2021 (ver REINALDO, 2021). 
Na francesa L'Occitane, também comercializada no Brasil, podemos encontrar linhas como Precieuse Immortele, Collection Divine (que têm cremes como Divine Immortele, Regard divin immortele - algo como divina imortal e olhar/ aspecto divino imortal), produtos como Harmonie divine (a harmonia divina é possível ser comprada em creme e sérum), além de produtos com perfectrice (perfeição), sublime e o huille jeunesse divine (óleo ou azeite da juventude divina). O que nos lembra a relação ancestral, mágica e semiótica entre nome e coisa.

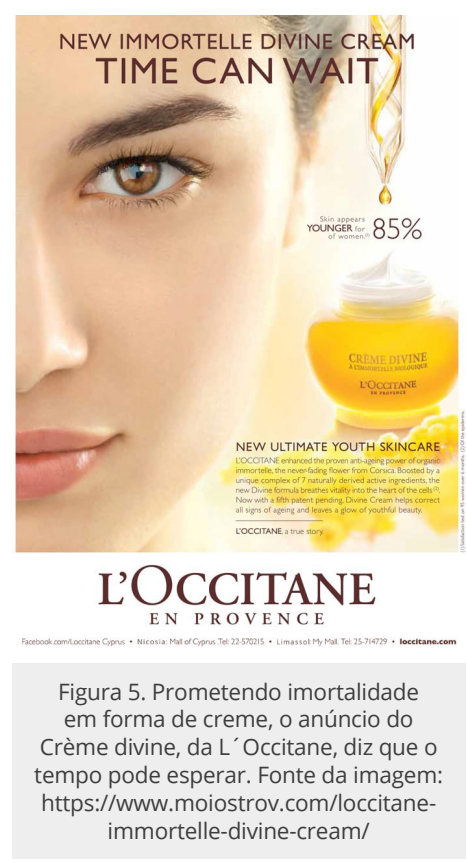

Na magia, o domínio das causas pode ajudar a controlar os efeitos — as origens da semiótica se enraízam nas práticas mágicas. A confiança imperturbável na eficiência do ato mágico concorria com o poder da igreja medieval, que considerava a magia pura como pagã. Estigma que não conseguiu conter a presença dessa atividade nas doutrinas judaico-cristãs, como se pode perceber no milagre dos santos ou na transubstanciação eucarística. Com a modernidade, a magia, incompatível com o espírito científico - Max Weber caracteriza o período como desencantado - não poderia sobreviver senão em formas degeneradas (NÖTH, 1996).

Para além das práticas mânticas, das superstições e das narrativas (a chamada magia fictícia, presente, por exemplo, em contos populares), a magia 
sobrevive no mundo científico, desencantado, na forma de magia metafórica - "tal como é encontrada, por exemplo, nas promessas da publicidade nas mídias que descrevem os produtos com epítetos tais como 'mágico' ou 'sobrenatural'", diz Nöth (1996). Se, por um lado, essas figuras retóricas não exigem "nenhuma crença literal em efeitos realmente mágicos e não pressupõem uma mentalidade arcaica", por outro, seu alvo não é tão diferente daquele da prática dos magos: "Ambos querem o máximo de influência sobre o público" (NÖTH, 1996, p. 33).

Ainda nas prateleiras das farmácias ou lojas de cosméticos e perfumaria não é incomum ler nos rótulos a palavra "efeito". Já não está mais em primeiro plano a saúde da pele, mas a impressão que ela causa. A pele, como um screen, assume "efeitos", que podem ser o blur (muito conhecido entre as blogueiras como "efeito photoshop", o software de edição de imagens mais usado em todo o mundo, desenvolvido pela companhia americana Adobe), o efeito glam e o efeito lift (em algumas versões lê-se "efeito tensor").

Uma pesquisa no Google com as palavras "efeito cinderela" apresenta, aproximadamente, 580 mil resultados; entre os termos que se repetem nas páginas que contêm a expressão, encontramos: ageless (que, como num conto de fadas, promete apagar os efeitos do tempo - lembrando não exatamente Cinderela, mas outra heroína de conto de fadas: Bela Adormecida, a princesa que dorme enquanto o tempo não afeta seu corpo ou feições, que permanecem intactos no tempo da longa espera até a chegada do príncipe), ageless instantly, botox mágico e botox sem agulha (ou seja, máxima satisfação sem riscos ou sofrimento).

Com frequência, aparece também a palavra "bálsamo" ligada aos produtos da indústria cosmética. Diz-se bálsamo aquilo que alivia, preserva, perfuma e cura. Na Bíblia, a palavra de Deus é um bálsamo regenerador. No Antigo Testamento, está associado à rainha de Sabá. O Bálsamo de Gileade só era produzido na Terra Prometida, que ficava a oeste do Rio Jordão. Gileade (Gênesis 37: 25; Josué 22: 15,32; Salmo 60:7). Embalsamar é conservar a partir da proteção. O corpo embalsamado não se deteriora porque está livre de organismos oxidantes, a salvo da podridão e de substâncias corrosivas. Em sentido figurado, o bálsamo é um consolo, um lenitivo, mas também uma forma de distinção - vale lembrar que, no antigo Egito, o embalsamamento é reservado a um grupo de seletos. O que corresponde ao discurso meritório e autoindulgente presente nos apelos publicitários: "você merece esse 
cuidado...". Os produtos das prateleiras agem não apenas como bálsamos na epiderme, mas penetram nas almas e prometem agir sobre a autoestima. Uma autoestima que pode ser acessada pelo cartão de crédito. Um produto que atende por Creme Ageless Instantly Efeito Cinderela Botox Mágico é comercializado pelo site das Lojas Americanas por R\$169,99 (caixa com 15 unidades, em fev. de 2020).

Mas a Cinderela que conhecemos como a enteada maltratada pela madrasta e suas filhas nem sempre teve um final feliz. Em seu História Noturna-decifrando o sabá, Carlos Ginzburg diz que essa história remonta ao século IX, na China.

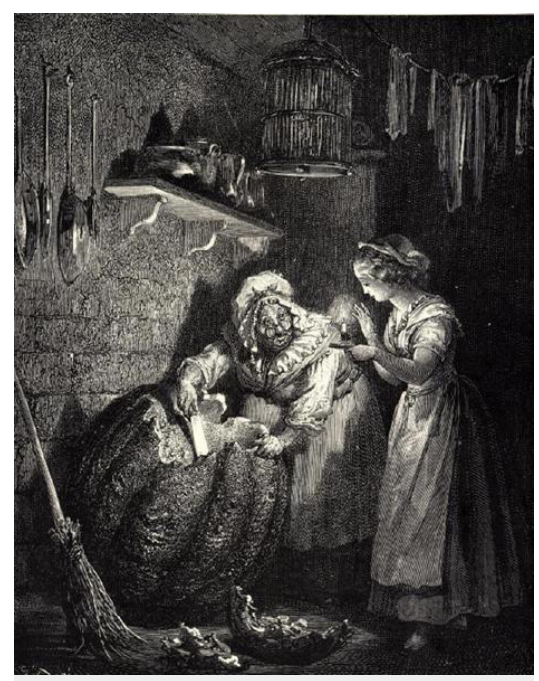

Figura 6. Cinderela, por Gustave Doré. Fonte da imagem: https://www.wikiart.org/pt/ gustave-dore/cinderela-0

Recuperando a história da França feudal, a França pré-revolução francesa ("a história dos não iluminados, no lluminismo"), Robert Darnton (1988) revela que, em uma das versões anteriores às que conhecemos, Cinderela se torna uma empregada doméstica para fugir dos assédios do pai. Em outra variante, a madrasta tenta empurrá-la para dentro do fogão e, por engano, incinera sua própria filha. Na versão europeia mais remota, diz Ginzburg (2012), a história repete o mesmo esquema das fórmulas mágicas: há o signo da proibição (interdição em ir ao baile), os objetos mágicos (sapatos e vestidos doados pelos ajudantes mágicos), a transgressão e a fuga. Na versão de 
Perrault, o ajudante mágico é uma fada madrinha. Mas, com frequência, diz Ginzburg, essa função pode ser desempenhada por uma planta ou por um animal - que pode ser uma vaca ou um peixe (na Índia), uma ovelha ou um carneiro (na Escócia), ou ainda uma cabra ou um touro - que a heroína tenta proteger.

Independente das variações do conto, a história da Cinderela é a da protagonista que sai das sombras, das cinzas (Cinderela vem de cinder, em inglês, as cinzas da cozinha com fogão a lenha, onde dormia), ornada com adereços mágicos que lhe proporcionam a entrada num mundo de felicidade. Como na alquimia, há a mudança de substâncias ordinárias em substâncias valiosas. O ouro, a fortuna, a felicidade, o casamento real... dependem de um segredo, o segredo alquímico da transmutação.

Dentre os químicos comercializados atualmente, os cosméticos são os que mais se beneficiam da aura do sagrado, que etimologicamente diz do que está separado. Diferente de fármacos como os remédios, que precisam ter suas bulas em linguagem clara e compreensível, o sucesso de um cosmético não está no elenco da fórmula — obrigatório para sua comercialização nas prateleiras dos grandes centros comerciais, mas nem sempre decifrável para o consumidor médio, que desconhece a função dos químicos descritos na composição. Aquele que tem acesso ao segredo acede também à esfera do confidencial, do reservado.

\section{Considerações finais: o rosto e as sombras, num tempo em que tudo se expõe}

Luz e sombra, velar e desvelar, não apenas caracterizam a atividade do rosto, mas fazem parte de uma das técnicas de maquiagem mais ancestrais, o contour. Também chamada contouring, a técnica chega ao século XX, inicialmente via maquiadores de cinema nos anos 1950 e 1960, e nos 1980 e 1990 cai nas graças dos profissionais da moda. No século XXI, o contour é ressuscitado por Kim Kardashian, que se notabiliza por tutoriais em redes sociais. Se antes o contour mimetizava o rosto de um tigre ou de uma águia e tinha funções ritualísticas, hoje as sombras esculpem um rosto mais "harmonioso" - harmonia e harmonização que, por sua vez, viraram palavras-chave em consultórios dermatológicos, dentários e de cirurgiões plásticos, contribuindo para a uniformização seriada das faces. 


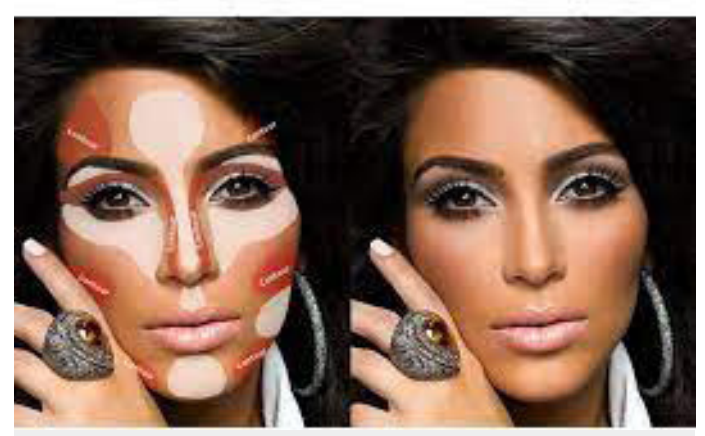

Figura 7. O jogo de sombreamentos da técnica de maquiagem contouring, popularizada pelos tutoriais da socialite Kim Kardashian. Fonte da imagem: https://harpersbazaar.uol.com. br/beleza/tudo-sobre-a-tecnica-de-maquiagem-contouring/

No contour dos tutoriais das celebridades fashion, os pigmentos mais escuros são aplicados nos pontos que se pretende afilar ou alongar - como nariz (especialmente de pessoas negras, com narinas mais largas) e têmporas. Os pigmentos mais claros ou luminosos (cujas composições podem conter cintilância ou glitter) são aplicados nas áreas do rosto para torná-las mais proeminentes. Em contraponto às sombras, essas áreas "saltam", destacam-se, contribuindo para clarear peles escuras, afinar traços e criar volumes ou, ainda, aumentar os olhos orientais.

Contornar é moldar ou cinzelar — o site Her World fala em modelar e entaIhar um jeito de conseguir face e nariz mais finos sem cirurgia plástica (no original: "Shape and sculpt your way to a slimmer face and nose - sans plastic surgery!". ${ }^{7}$ Escultura que segue um conjunto de regras mais ou menos rígidas sempre na tentativa de criar ou valorizar traços ocidentais e brancos ${ }^{8}$. Mas o contouring não fica na paleta dos marrons e beges. Os tons rosados garantem a pele corada — signo não apenas de viço e frescor, mas também dos estados de espírito mais "elevados", uma vez que a face levemente ruborizada remete ao pudor castiço que se espera de uma pessoa (especialmente de uma mulher) recatada, "honesta",

7 Disponível em: <https://www.herworld.com/beauty/your-ultimate-guide-easy-contouring-asianface-shapes-all-under-5-minutes>.

8 Mesmo a K-Beauty, novidade fashion coreana que se destaca no mundo da moda, articula os mesmos padrões ocidentais (no original: "Forget everything you know about over-the-top Kardashianinspired contouring. The K-beauty contour is a pretty, subtle alternative, perfect for anyone looking to achieve that fresh, no-makeup look", https://beautytap.com/2017/05/k-beauty-contour/). Mas o que promete libertar os rostos do padrão de contour das Kardashians não promove exatamente uma valorização dos traços orientais. No site, as modelos têm olhos com lentes de contato coloridas, sendo uma delas de cabelos aloirados. 
"pura". O rubor também aponta para a claridade da pele, uma vez que a dilatação dos vasos sanguíneos de capilaridade superficial só é mais evidente nas pessoas de epiderme mais fina e clara - note-se ainda que alguns argumentos em favor da escravidão chegavam mesmo a compreender o não enrubescimento aparente do rosto de pele negra como um indício da falta de sentimentos "nobres", como decoro, constrangimento ou indignação.

Embora este artigo se dedique à maquiagem, nesta pesquisa (que tem caráter mais amplo), constato que, além da pintura facial, são variados os aplicativos de celular com funções que identificam pontos específicos do rosto - como olhos, bochechas, boca, nariz - e aplicam camadas de cores, além de modificar contornos com jogos de sombreamentos e iluminação. Funções que (sugestivamente) são chamadas de embelezamento facial aumentam o tamanho dos olhos ou os arredondam (numa tentativa de "ocidentalização" dos traços indígenas ou asiáticos), coram bochechas, deixam os lábios mais salientes e afinam têmporas e narinas.

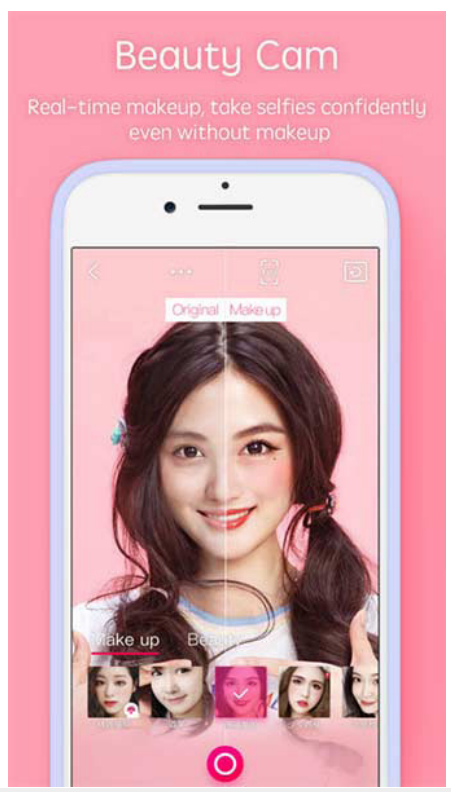

Figura 8. Sobre o aplicativo Pitu, diz a publicação 15+ Best Selfie Beauty and Retouching Apps: "One click to retouch and makeup. Bigger eyes, slimmer, brighten, foundation, eyebrow, eye shadow, eyelashes, blusher, lipstick, hair dye, etc. Smoother skin, slimmer body, one-tap beauty, filters, fun stickers". Fonte: https://ilols.com/photo-beautifier-apps-iphone/ 
Se antes a prática do black face - em que atores brancos pintavam o rosto de tinta preta em espetáculos humorísticos e se comportavam de maneira caricatural - tinha como finalidade aviltar e ridicularizar a cultura negra e traços fisionômicos, hoje os aplicativos de modificação facial revelam um racismo que é mais perverso e sutil.

Num tempo em que tudo se expõe, tempo de tamanha claridade e grande circulação de rostos (e a imagem do rosto é, dentre todas as imagens produzidas e difundidas, a mais ubíqua), só as sombras podem nos proporcionar alguma possibilidade de acomodar o olhar e enxergar. E o que elas têm mostrado tem correspondências com as nossas sombras internas, facetas que desconsideramos, que esquecemos, que escondemos. Sombreamentos que falam dos nossos preconceitos, dos nossos medos e dos nossos desejos recalcados.

Antes, a pele recebia tintas para mimetizar animais totêmicos, como ursos, raposas, antílopes ou serpentes em rituais de caça, de guerra, de cura, em celebrações da colheita, e em cerimônias de luto ou casamento. Os pigmentos vinham de raízes, folhas, óleos, vísceras e minerais. Obtê-los requeria uma intimidade mística com a natureza e obediência a calendários e a regras sociais muito específicos.

Hoje, mesmo sem se dedicar à pintura ritualística, a pintura facial ainda conserva traços de ancestralidade (criação de personagens, anulação do sujeito, encontro com um eu que se revela no exercício da trucagem...). Mas, por mais que se modifiquem seus usos e práticas, a maquiagem facial se volta sempre para o mistério. Mídia instável, suspeita e ao mesmo tempo confiável porque singularmente familiar, o rosto é superfície e abismo. O mistério não se desfaz, "o eu por trás de mim" (como diz G. Rosa no conto O espelho, de Primeiras estórias) não se anula nos filtros - sejam físicos, químicos ou matemáticos (formados por píxeis). Ele se reinventa. E as novas tecnologias exigem de nós, pesquisadores, outras posturas metodológicas. Encaremo-las! Encaremo-nos!

Gabriela Reinaldo é professora permanente do Programa de Pós-Graduação em Comunicação do Instituto de Cultura e Arte da Universidade Federal do Ceará ICA-UFC. É doutora em Comunicação e Semiótica pela PUC/SP.

gabriela.reinaldo@gmail.com 


\section{Referências}

BARHAM, L. S. Systematic Pigment Use in the Middle Pleistocene of South-Central Africa. Current Anthropology, vol. 43, no. 1, 2002, pp. 181-190. JSTOR, www.jstor.org/ stable/10.1086/338292. Accessed 10 Mar. 2021) https://www.jstor.org/stable/10.1086/3 38292?origin=JSTOR-pdf\&seq=1 Também disponível em: http://in-africa.org/wp-content/ uploads/2012/12/Barham-2002-CA-pigment-M-Ple-SC-Africa.pdf.

BASTEN, F. E. Max Factor - The Man who Changed the Faces of the World. New York: Arcade Publishing, 2008 (versão ebook Kindle)

BELTING, H. Antropología de la imagem. Buenos Aires: Katz Editores, 2007.

Facce - una storia del volto. Roma: Carocci Editore, 2015.

CONNOR, S. Body art made its mark 300,000 years ago, scientists claim. The Independent. London, p. 1-5. 01 Não é um mês valido! 2009. Disponível em: https://www.independent. co.uk/news/science/body-art-made-its-mark-300-000-years-ago-scientists-claim-6231646.html. Acesso em: $1^{\circ}$ jan. 2021.

COURTINE, J.-J.; COURTINE, H. L'Histoire du visage - exprimer et taire ses émotions (du XVIe siècle au début du XIXe siècle). Paris: Payot, 2007.

CYRULNIK, Boris. O nascimento do sentido. Lisboa: Editora Piaget, 1995.

DARNTON, R. O grande massacre dos gatos: e outros episódios da história cultural francesa. Rio de janeiro: Graal, 1988.

DELLA PORTA, G. B. De humana phyisiognomonia. 1586. Disponível em: <http:// gutenberg.beic.it/view/action/nmets.do?DOCCHOICE=1285865.xml\&dvs=15172504406 26 807\&locale=pt_BR\&search_terms=DTL4\&show_metadata=true\&adjacency; $=$ \&VIEWE R;_URL=/view/action/nmets.do?\&DELIVERY_RULE_ID=7\&divType;=\&usePid1 =true\&usePi d2=true $>$. Acesso em: 28 jan. 2018.

GINZBURG, C. História noturna: decifrando o sabá. São Paulo, Companhia das Letras, 2012.

HIMELFARB, E. J. Prehistoric Body Painting. Archaeology: a publication of the Archaeological Institute of America. Boston, p. 1-2. jul. 2000. Disponível em: <https://archive. archaeology.org/0007/newsbriefs/zambia.htm>. Acesso em: $1^{\circ}$ jan. 2021.

LEONE, M. Nature and culture in visual communication: Japanese variations on Ludus Naturae. Semiotica, vol. 2016, no. 213, 2016, pp. 213-245. Disponívem em: <https://doi. org/10.1515/sem-2015-0145>. Em <https://www.degruyter.com/document/doi/10.1515/ sem-2015-0145/html>. Acesso em" $1^{\circ}$ jan. 2021.

. The semiotics of the face. Torino: Lexia Rivista di Semiotica - Youtube, 2018. (98 min.), son., color. Massimo Leone, University of Turin Incontri sul Senso (Meetings on Meaning) 2017-2018 20/02/2018. Disponível em: <https://www.youtube.com/watch?v=o-OWXQBZjqM>. Acesso em: $1^{\circ}$ jan. 2020. 
LOTMAN, I. Universe of the mind: a semiotic theory of culture. Bloomington: Indiana University Press, 1990.

NÖTH, W. Semiótica da magia. Revista USP: Dossiê Magia, São Paulo, v. 31, p. 30-41, set/ nov. 1996. Disponível em: <http://www.revistas.usp.br/revusp/article/view/25957/27688>. Acesso em: $1^{\circ}$ dez. 2017.

PROSS, H.; HANNO, B. Introducción a la ciencia de la comunicación. Barcelona: Anthropos, 1990.

REINALDO, G. As faces de Hans Belting. In: BRASIL, A.; PARENTE, A.; FURTADO, B. (Org.). Imagem e exercício da liberdade: cinema, fotografia e artes - imagem contemporânea III. 1ed.Fortaleza: Imprensa Universitária, 2020, v. 1, p. 86-108.

O rosto nu: sobre o disfarce da maquiagem. Designis, Rosario, v. 01, n. 01, p. 101-109, set. 2021. Edição "HORS SERIE 01", com título: El rostro en el horizonte digital latinoamericano. Disponível em: <https://www.designisfels.net/hors-serie/el-rostro-en-el-horizonte-digital-latinoamericano/>. Acesso em: 02 nov. 2021.

. Rosto na mídia e rosto como mídia: as contribuições de Hans Belting para o estudo do rosto. Revista Famecos, [S.L.], v. 26, n. 2, p. 32442-32453, 17 dez. 2019. EDIPUCRS. Disponível em: <https://revistaseletronicas.pucrs.br/ojs/index.php/revistafamecos/article/ view/32442>. Acesso em: $1^{\circ}$ jan. 2020.

ROSA, J. G. O espelho. In: Primeiras estórias. Rio de Janeiro: José Olympio, 1978

SACKS, O. O homem que confundiu sua mulher com um chapéu. São Paulo: Companhia das Letras, 1997.

O olhar da mente. São Paulo: Companhia das Letras, 2010.

SAUNDERS, R. Physiognomie and chiromancie, metoposcopie: the symmetrical proportions and signal moles of the body, fully and accurately handled; with their naturalpredictive-significations. The subject of dreams; divinative steganographical, and Lullian sciences. Where unto is added the art of memorie. 1653. Disponível em: <https://wellcomelibrary.org/item/b2026530x\#?c=0\&m=0\&s=0\&cv=7\&z=-0.6573,0,2.3146,1.4539>.

Acesso em: 26 jan. 2017

UPDIKE, J. Makeup And make-believe: Max Factor's life of beautification. The New Yorker. New York, p. 124-128. 1 set. 2008. Disponível em: <https://www.newyorker.com/ magazine/2008/09/01/makeup-and-make-believe>. Acesso em: $1^{\circ}$ fev. 2018.

WATTS, I. Pigments. In: Gilbert A.S. (eds) Encyclopedia of Geoarchaeology. Encyclopedia of Earth Sciences Series. Springer: Dordrecht, 2017. <https://doi. org/10.1007/978-1-4020-4409-0_37>. Disponível em: <https://link.springer.com/ referenceworkentry/10.1007/978-1-4020-4409-0_37> e em <https://www.academia. edu/26910849/Pigments_in_Encyclopedia_of_Geoarchaeology_proofs_2016_pdf>. Acesso em: 02 jan. 2021. 
. The pigments from Pinnacle Point Cave 13B, Western Cape, South Africa. Journal Of Human Evolution, [S.L.], v. 59, n. 3-4, p. 392-411, set. 2010. Elsevier BV. <http://dx.doi. org/10.1016/j.jhevol.2010.07.006>. Disponível em: <https://www.sciencedirect.com/ science/article/abs/pii/S0047248410001326>. Acesso em: 03 fev. 2021.

ZUCCOLIN, G. The speculum phisionomie by Michele Savonarola. In: Universality of Reason. Plurality of Philosophies. 16-22 September 2007. Palermo, Italy. Disponível em: <https://www.academia.edu/2539598/The_Speculum_phisionomie_by_Michele_Savonarola>. Acesso em: 28 jan. 2018.

Artigo recebido em 27/04/2021 e aprovado em 30/05/2021. 